\section{SAT0679 ARE ADULT TRAJECTORIES OF WEIGHT OVER A LIFETIME LINKED TO FOOT PROBLEMS YEARS LATER?}

A.B. Dufour ${ }^{1}$, E. Losina ${ }^{2}$, H.B. Menz ${ }^{3}$, M.P. LaValley ${ }^{4}$, M.T. Hannan ${ }^{1} .{ }^{1}$ Institute for Aging Research, Hebrew SeniorLife; ${ }^{2}$ Brigham and Women's Hospital, Boston, United States; ${ }^{3}$ School of Allied Health, la Trobe University, Bundoora, Australia; ${ }^{4}$ Biostatistics, Boston University, School of Public Health, Boston, United States

Background: Obesity and foot problems are common in older adults and associated with many negative health outcomes. Better understanding of the consequences of patterns of weight change may lead to better prediction and dealing with foot pain and foot disorders.

Objectives: This study identified longitudinal trajectories of weight in a populationbased study and examined the association of these groups with current foot problems.

Methods: We used 28 measures of weight over 57 years to identify trajectories of weight in 2445 members of the Framingham Foot Study using k-means longitudinal cluster analysis. Foot examinations (2002-2008) recorded presence of foot pain, hallux valgus, claw toes, hammer toes and overlapping toes on each foot. Associations between weight group membership and foot problems at time of foot exam, adjusted for age and sex, were examined using logistic regression with generalized estimating equation correction for two feet per subject. The reference group used for analysis was the group with the lowest weight trajectory ("E").

Results: We found 5 trajectories of weight, representing relatively constant patterns over time, with weight increasing from groups $E$ to $A$. Those in group " $E$ " were more likely to be older, while the youngest were in group " $A$ " group. "E" had the lowest prevalence of foot pain (14\%) while group " $A$ " had the highest $(22 \%)$. Similarly, group "A" had the lowest prevalence of hallux valgus, while group "E" had the highest (36\%) (Table 1).

Compared to group "E", other groups were more likely to have foot pain (ORs $1.57-3.50$, Table 2) and less likely to have hallux valgus (ORs $0.73-0.99$ ). For claw toes, all but one group were more likely to have claw toes compared to group "E". Groups "A" and "D" were more likely to have hammer toes (ORs 2.40 and 1.35 , respectively) compared to group " $\mathrm{E}$ ". We found no associations between overlapping toes and group membership.

Table 1. Participant characteristics by weight trajectory group

\begin{tabular}{lccccc}
\hline & $\mathrm{A}$ & $\mathrm{B}$ & $\mathrm{C}$ & $\mathrm{D}$ & $\mathrm{E}$ \\
& $\mathrm{N}=201 /$ & $\mathrm{N}=644 /$ & $\mathrm{N}=617 /$ & $\mathrm{N}=506 /$ & $\mathrm{N}=477 /$ \\
& 402 feet & 1288 feet & 1233 feet & 1011 feet & 954 feet \\
\hline Age (years) & $63 \pm 9.0$ & $69 \pm 11.2$ & $68 \pm 10.5$ & $66 \pm 9.7$ & $71 \pm 11.9$ \\
Body mass index $\left(\mathrm{kg} / \mathrm{m}^{2}\right)$ & $37 \pm 6.3$ & $27 \pm 3.3$ & $29 \pm 4.0$ & $31 \pm 4.3$ & $23 \pm 2.9$ \\
Female & $76(19 \%)$ & $1036(80 \%)$ & $478(39 \%)$ & $230(23 \%)$ & $918(96 \%)$ \\
Foot pain & $88(22 \%)$ & $240(19 \%)$ & $222(18 \%)$ & $186(18 \%)$ & $135(14 \%)$ \\
Hallux Valgus & $57(14 \%)$ & $408(32 \%)$ & $267(22 \%)$ & $169(17 \%)$ & $341(36 \%)$ \\
Claw Toes & $9(2 \%)$ & $29(2 \%)$ & $29(2 \%)$ & $24(2 \%)$ & $18(2 \%)$ \\
Hammer toes & $89(22 \%)$ & $246(19 \%)$ & $197(16 \%)$ & $165(16 \%)$ & $174(18 \%)$ \\
Overlapping toes & $14(3 \%)$ & $99(8 \%)$ & $73(6 \%)$ & $48(5 \%)$ & $90(9 \%)$ \\
\hline
\end{tabular}

Table 2. Association between weight trajectory group membership and foot problems, adjusted for age and sex

\begin{tabular}{lcccc}
\hline & A vs. E & B vs. E & C vs. E & D vs. E \\
\hline Foot pain & $3.5(2.49,4.9)^{\star}$ & $1.57(1.25,1.98)^{\star}$ & $2.16(1.68,2.77)^{\star}$ & $2.63(2.00,3.47)^{\star}$ \\
Hallux Valgus & $0.72(0.51,1.02)$ & $0.99(0.82,1.18)$ & $0.86(0.7,1.06)$ & $0.77(0.61,0.99)^{\star}$ \\
Claw toes & $3.97(1.57,10)^{\star}$ & $1.52(0.83,2.79)$ & $2.24(1.17,4.29)^{\star}$ & $3.1(1.51,6.38)^{\star}$ \\
Hammer toes & $2.4(1.71,3.38)^{\star}$ & $1.2(0.96,1.5)$ & $1.12(0.87,1.45)$ & $1.35(1.02,1.79)^{\star}$ \\
Overlapping toes & $0.78(0.41,1.48)$ & $0.93(0.68,1.27)$ & $0.87(0.6,1.25)$ & $0.85(0.55,1.32)$ \\
\hline${ }^{*} P<0.05$ & & & &
\end{tabular}

Conclusions: Trajectories with higher weight over a lifetime had increased odds of foot pain and claw toes, and decreased odds of hallux valgus later in life. These results provide evidence that having lower weight over one's lifetime can reduce the likelihood of foot problems later in life.

Disclosure of Interest: None declared

DOI: 10.1136/annrheumdis-2017-eular.3018

\section{SAT0680 THE IMPACT OF DISEASE ACTIVITY DURING PREGNANCY IN WOMEN WITH SLE ON THE BIRTH WEIGHT OF THE CHILD}

A.C.G. Skorpen $^{1,2}$, S. Lydersen ${ }^{3}$, I.-M. Gilboe ${ }^{4}$, K.Å. Salvesen $^{5}$,

M. Wallenius ${ }^{1,2}$. 1 National advisory unit on Pregnancy and Rheumatic Diseases, Trondheim University Hospital; ${ }^{2}$ Department of Neuromedicine and Movement Science, ${ }^{3}$ Regional Center for Child and Youth Mental health and Child Welfare, Norwegian University of Science and Technology, Trondheim; ${ }^{4}$ Department of Rheumatology, Oslo University Hospital Rikshospitalet, Oslo; ${ }^{5}$ Department of Laboratory Medicine, Children's and Women's Health, Norwegian University of Science and Technology, Trondheim, Norway

Background: Mean birthweight is lower in children of SLE-mothers than in references. Active disease in pregnancy is considered one of the risk factors. Objectives: The aim of this study was to explore the association of disease activity in women with SLE in pregnancy and the birth weight of the child expressed as mean birth weight and mean z-score for birth weight.

Methods: We linked data from RevNatus with data from the Medical Birth
Registry of Norway (MBRN). RevNatus is a Norwegian nationwide prospective observational register including women with an inflammatory rheumatic disease when planning pregnancy or after conception. The register is administered by the National advisory unit on pregnancy and rheumatic diseases. Women 18 years or older are recruited and followed-up in each trimester of pregnancy and at 6 weeks, 6 months and 12 months after birth. MBRN is a national birth registry. The population constituted all singleton live births recorded in MBRN in the period $2006-2014$. The births in women diagnosed with SLE in MBRN and included in RevNatus formed the patient group $(n=180)$. The references were all other births $(n=498849)$. Mean birth weight in the patient group was compared to mean birth weight in the general obstetric population. We calculated z-score for birth weight adjusted for gestational age and sex. The target population was then split in two groups according to disease activity assessed in the 2 nd trimester, and compared to references. One-way ANOVA was performed to compare SLE-women without active disease, SLE-women with active disease and references from the general obstetric population.

Results: The mean birth weight and mean z-score were both significantly lower in women with SLE compared to references.

Table 1. Mean birth weight and z-score in references and in women with SLE

\begin{tabular}{lcccc}
\hline Mean (SD) & References $n=497959$ & SLE $n=180$ & Mean difference $(95 \% \mathrm{Cl})$ & $\mathrm{p}$ \\
\hline Birth weight $\mathrm{g}$ & $3518(588)$ & $3091(691)$ & $426(325,528)$ & $<0.001$ \\
Z-score & $-0.11(0.98)$ & $-0.59(0.87)$ & $0.47(0.33,0.62)$ & $<0.001$
\end{tabular}

When comparing three groups, a significantly lower mean birth weight and mean $z$-score remained between women without active disease and references and women with active disease and references. There were no significant differences between the two disease groups.

Table 2. Mean birth weight and z-score in references and in women with SLE according to disease activity status

\begin{tabular}{|c|c|c|c|c|}
\hline Mean (SD) & $\begin{array}{c}\text { References } \\
\mathrm{n}=497,959\end{array}$ & $\begin{array}{c}\text { No disease activity }{ }^{\dagger} \\
n=85\end{array}$ & $\begin{array}{c}\text { Mean difference } \\
(95 \% \mathrm{Cl})\end{array}$ & $p$ \\
\hline Birth weight $g$ & $3518(482)$ & $3133(587)$ & $385(260,510)$ & $<0.001$ \\
\hline Z-score & $-0.11(0.98)$ & $-0.64(0.81)$ & $0.53(0.32,0.74)$ & $<0.001$ \\
\hline Mean (SD) & $\begin{array}{c}\text { References } \\
\mathrm{n}=497,959\end{array}$ & $\begin{array}{c}\text { Disease activity }{ }^{\ddagger} \\
n=63\end{array}$ & $\begin{array}{c}\text { Mean difference } \\
(95 \% \mathrm{Cl})\end{array}$ & $p$ \\
\hline Birth weight g & $3518(588)$ & 2991 (802) & $526(62-354)$ & $<0.001$ \\
\hline Z-score & $-0.11(0.98)$ & $-0.54(0.90)$ & $0.43(0.18,0.67)$ & 0.001 \\
\hline Mean (SD) & $\begin{array}{l}\text { No disease activity } \\
n=85\end{array}$ & $\begin{array}{l}\text { Disease activity } \\
\quad n=63\end{array}$ & $\begin{array}{l}\text { Mean difference } \\
\quad(95 \% \mathrm{Cl})\end{array}$ & $p$ \\
\hline Birth weight $g$ & $3133(587)$ & 2991 (802) & $141(-50,333)$ & 0.15 \\
\hline Z-score & $-0.64(0.81)$ & $-0.54(0.90)$ & $-0.10(-0.40,0.22)$ & 0.53 \\
\hline
\end{tabular}

†LAI-P $=0 .{ }^{\ddagger}$ LAI- $P>0$

Conclusions: Mean birth weight and Z-score was significantly lower in women with SLE compared to the general obstetric population. There were no significant differences in diseased women with active as opposed to quiescent disease.

Disclosure of Interest: None declared

DOI: 10.1136/annrheumdis-2017-eular.5820

\section{SAT0681 RISK OF ACTIVE TUBERCULOSIS IN PATIENTS WITH INFLAMMATORY ARTHRITIS RECEIVING TNF-INHIBITORS}

A.M. Gheorghiu ${ }^{1,2}$, A. Garaiman ${ }^{1,2}$, A. Radu ${ }^{1,2}$, A. Soare ${ }^{1,2}$, V. Aramă ${ }^{2,3}$, D. Bumbăcea ${ }^{2,4}$, R. Dobrotă ${ }^{1,2}$, R. Oneata ${ }^{1,2}$, S. Pintilie $^{1,2}$, M. Milicescu ${ }^{1,2}$

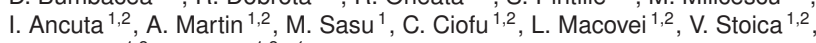
M. Bojinca ${ }^{1,2}$, C. Mihai ${ }^{1,2}{ }^{1}$ Internal Medicine and Rheumatology, Cantacuzino Hospital; ${ }^{2}$ Carol Davila University of Medicine and Pharmacy; ${ }^{3}$ Infectious Diseases 1, Matei Bals National Institute for Infectious Diseases; ${ }^{4}$ Dept. of Pneumology, Elias Emergency University Hospital, Bucharest, Romania

Background: Tuberculosis (TB) is a major concern in patients receiving TNF inhibitors (TNFi).

Objectives: To assess the incidence of active TB and the efficacy of TB prevention measures in a large, single-center cohort of patients with rheumatoid arthritis (RA), psoriatic arthritis (PsA) and ankylosing spondylitis (AS) receiving TNFi. Methods: Data of all patients in whom treatment with TNFi was initiated in our rheumatology clinic from January 1st 2002 until December 31st 2015 have been retrospectively analysed. The cohort was divided into 2 groups per the mandatory latent TB infection (LTBI) screening method at baseline: tuberculin skin test (group TST), and QuantiFERON ${ }^{\circledR}$-TB Gold test (group QFT). The incidence of active TB was analysed for each group and compared to TB incidence data in general population.

Results: 653 patients were included (344 RA, 52 PsA, 257 AS); 324 patients belonged to the TST and 329 to the QFT group. The number of active TB cases/ time of exposure to TNFi (person-years, PY) was 17/2002.6 and 7/1041.2 respectively, accounting for an incidence of 848.9 and 672.3 cases per $10^{5} \mathrm{PY}$, about 8 times higher ( 8.3 and 8.8 for TST, respectively QFT group) than the average TB during the period of exposure to TNFi. LTBI reactivations per total TB cases were only $4 / 17$ and $2 / 7$, respectively, too few to identify statistically significant differences between the 2 LTBI screening protocols. Only 10 patients 